\title{
A New Cost EFFicienCy Measure for Not-FOR-Profit FiRMS: EVIDENCE OF A LINK BETWEEN INEFFICIENCY AND LARGE ENDOWMENTS
}

\author{
JOSEPH P. HUGHES
}

\author{
MAY 2011 \\ WORKING DRAFT
}

\section{DEPARTMENT OF ECONOMICS \\ RUTGERS UNVERSITY NEW BRUNSWICK, NJ 08901}

\begin{abstract}
Cost functions and cost efficiency are commonly estimated for industries with detailed data on production and cost, both for firms that are for profit as well as not for profit. The data on not-for-profits obtained from the IRS Form 990 lack these details and, consequently, encourage substitution of the ratio of program expenses to total expenses to gauge performance. While a larger program expense ratio captures better administrative cost efficiency, it does not gauge best-practice cost and the extent to which an organization's administrative costs exceed best practice.

Using the Form 990 data, this study constructs an administrative cost function for not-for-profits and uses the distribution-free technique of estimating a best-practice cost frontier to gauge the relative efficiency of not-forprofit organizations. Focusing on not-for-profit hospitals and their holdings of liquid assets, the empirical evidence is consistent with Jensen's free cash flow hypothesis: hospitals holding liquid assets in excess of a benchmark have lower program expense ratios and lower cost efficiency. In addition, the CEOs of more cost efficient hospitals earn higher compensation. The agreement of the evidence on agency problems related to excess holdings of liquid assets from the program expense ratio and administrative cost efficiency reinforce the credibility of the latter as a measure of the performance of not-for-profit organizations.
\end{abstract}

JEL codes: D24, D22

Keywords: not-for-profit, cost efficiency, free cash flow hypothesis

The author is grateful to the Research Council at Rutgers University for their financial support of this project, Vivian Valdmanis for her insightful comments, and to John Bowblis and Nicholas Galunic for their research assistance and advice while graduate students at Rutgers. 


\section{A NEW COST EFFICIENCY MEASURE FOR NOT-FOR-PROFIT FIRMS: EVIDENCE OF A LINK BETWEEN INEFFICIENCY AND LARGE ENDOWMENTS}

\section{Introduction}

Research on the performance of not-for-profit organizations has typically focused on their delivery of program services. The National Center for Charitable Statistics, a primary source of data on these organizations, collects information reported on the IRS Form 990 filed by these organizations. While these organizations do not generally pay taxes, most of them must nevertheless file the Form 990 annually with the IRS. It contains information derived from the income statement and balance sheet and divides all expenditures into three broad types: program, management, and fund-raising. Research using the Form 990 data to evaluate the performance of not-for-profit firms often employs the ratio of program expenses to total expenses to gauge the effectiveness of organizations in delivering services. For example, Core, Guay, and Verdi (2006) employ the program expense ratio to consider whether large endowments insulate not-for-profits from donor and market discipline and reduce their effectiveness at delivering program services. Desai and Yetman (2006) use the program expense ratio to examine how differences in the strictness of the regulation of not-for-profits by states influence their delivery of services.

A higher ratio of program expenses to total expenses suggests a not-for-profit organization delivers its program with fewer total expenses devoted to management and fund-raising. In short, it is more cost efficient than those with a lower program expense ratio. While a higher program expense ratio indicates higher cost efficiency, it does not indicate the best-practice level of costs and the divergence of any particular organization’s cost from best practice. Such divergence can gauge the extent of agency problems.

Many studies have directly estimated cost functions and cost efficiency for a variety of organizations, both for profit as well as not for profit. These studies typically focus on firms in industries with detailed data on production and cost, such as banking and health care. ${ }^{1}$ The data on not-for-profits obtained from the IRS Form 990 lack these details and, consequently, encourage substitution of the program expense ratio for the direct estimation of cost efficiency.

\footnotetext{
${ }^{1}$ For a review of the literature on bank production and efficiency, see Hughes and Mester (2009).
} 
While the IRS Form 990 data are not ideal for estimating cost efficiency, they nevertheless allow the estimation of a simple cost function and cost efficiency by adapting some of their variables to proxy for more standard outputs and inputs. The focus of most studies on program expense suggests that program expense can be used as a proxy for the primary output of a not-for-profit organization in the Form 990 data. The indirect cost of delivering any amount of program services is the sum of the management and fund-raising expenses. The fund-raising components of this sum of administrative costs point to another potential output, total contributions raised, which occasions some of these administrative costs. Thus, the Form 990 administrative cost function consists of the sum of management and fund-raising expenses as a function of the two outputs, program expense and total contributions raised. In addition, since labor and physical capital costs differ geographically, it is important to control for these differences in the cost function. In a particular not-for-profit sector, the best-practice organizations minimize the administrative expense of any given level of program service expense and contributed funds and input prices.

When most studies use the ratio of program expense to total expenses to gauge and compare the effectiveness of charities in delivering services, they implicitly assume that the quality of each dollar of program expense across charities is homogeneous. In using program expense as a proxy for the output of program services in the administrative cost function, the same assumption of homogeneity must be made.

This particular specification of the administrative cost function also permits an evaluation of the efficiency of fund-raising. If the cost function takes on a sufficiently flexible functional form such that the marginal administrative cost of an additional dollar of contributions raised is not necessary constant, the efficiency of fund raising can be investigated. And, if the specification includes an interaction between the two outputs, contributions raised and program services expenditures, the size of program services can influence funds raised so that the optimal level of fund-raising would depend on the size of the organization.

The administrative cost function can be estimated for any particular not-for-profit sector (industry). The standard estimation fits the cost function as an average of the data while the challenge to identify the bestpractice cost - the lowest costs observed in the sample - requires fitting the cost function as a lower frontier of the data and gauging the efficiency of each organization by the distance of its cost from this best practice cost frontier. Several techniques have been used in the literature to estimate the best-practice frontier. Since panel data are available, this study estimates the distribution-free frontier, which was developed by Berger (1993) 
from a panel data approach proposed by Schmidt and Sickles (1984). For an example of this frontier applied to banking data, see Altunbas, Evans, and Molyneux (2001), Berger and Hannan (1998), Berger and Mester (1997), and Stiroh (2000).

In this study, the plausibility of the cost efficiency estimates are investigated by re-estimating the model of Core, Guay, and Verdi (2006), which found that charities whose endowment exceeds an estimated benchmark have on average lower program expense ratios and higher executive compensation -- evidence that the reduction in managers' need to compete in the market for donors and services results in a shift of expenses from program to administration. This study confirms the plausibility of its frontier measure of administrative cost efficiency by finding evidence consistent with Core et al. that endowments in excess of the benchmark are associated with lower administrative cost efficiency. Several different characterizations of "excess endowment” all lead to the same conclusion: wealthy charities tend to be less administratively efficient than their poorer cousins. Moreover, higher administrative cost efficiency is associated with a higher predicted CEO compensation. The estimates obtained using administrative cost efficiency as the dependent variable are much more precise than those obtained using the program expense ratio.

While the study by Core et al. used data from the entire charitable sector covering many very different “industries,” this study focuses on the largest sector in the Form 990 data, health care, and, to narrow the data to a more homogenous “industry,” general hospitals (National Taxonomy of Exempt Entities Core Code E22). The data consist of a balanced panel of 1028 distinct not-for-profit hospitals in the United States over the period 1998-2003. Observations with implausible data, such as negative assets and liabilities, program expenses, contributions, and so on were eliminated. In addition, hospitals which reported "Payments to Affiliates,” line 16, were eliminated since their total expenses did not equal the sum of management, fundraising, and program expenses. Table 1 provides summary statistics of these data.

In contrast to the median total revenue, $\$ 23,149,532$, the mean, $\$ 77,332,098$, reflects the influence of some very large hospitals, the largest generating $\$ 1,698,971,684$ in revenue. The mean administrative cost, $\$ 10,138,015$ exceeds the median, $\$ 3,130,709$ and, not surprisingly, consists largely of management rather than fund-raising expense. Program services expense, 83.3 percent of total expenses, constitutes the largest expense category: on average, $\$ 64,586,493$, which is much larger than the median $\$ 18,310,289$. Fund raising, 0.63 percent of total expenses, generates on average 8.95 percent of total revenue. The median proportion of 
contributions to total revenue is 0.55 percent. Liquid holdings, the sum of cash, savings, and investment securities, termed “endowment” by Core, Guay, and Verdi (2006), amounts to \$31,180,048 on average. The largest holding is $\$ 34,650,000,000$. They focus on holdings of liquid assets to investigate agency problems related to excess cash discussed by Jensen (1986) in his paper on “free cash flow.” Fund balance, the difference between assets and liabilities, gives a more common measure of "endowment," however, it does not necessarily capture holdings of liquid assets. This investigation explores the existence of agency problems related to relatively large holdings of liquid assets using both the program expense ratio and administrative cost efficiency as performance metrics.

The sections that follow detail the specification and estimation of the administrative cost function, the calculation of the best-practice efficiency metric, and a test of its plausibility by using it to retrace the investigation of Core et al. to determine if the efficiency metric yields similar results at the same or better precision.

\section{The Administrative Cost Function, Scale Economies, and Efficiency}

The specification of the cost function must accomplish at least two goals. First, it should capture the essential outputs of the charity to the extent allowed by the Form 990 data so that convincing peer groups can be defined for comparing efficiency - that is, groups producing the same output, doing essentially the same thing. Second, the specification should allow sufficient flexibility that it does not attempt to impose, say, linear relationships on nonlinear data. The administrative cost function for firm $i$ in year $t$ is given by

$$
\ln C_{i t}=\ln C\left(\mathbf{y}_{i t}, \mathbf{w}_{i t}\right)+\ln \mu_{i}+\ln v_{i t}
$$

where ln is the natural logarithm; $C$ is administrative cost, the sum of management and fund-raising expenses; $y$ is a vector of two outputs, program services measured by program expenses and total contributions raised; $\boldsymbol{w}$, a vector of input prices, proxied by state and year dummy variables; $\mu$, a time-invariant efficiency factor; and $v$, a time-varying random error.

Equation (1) is estimated by using a translog functional form. The log form presents a problem for observations which report no contributions. To avoid loosing these observations, Core, Guay, and Verdi (2006), who also use a log specification in a different context, create a dummy variable which takes the value 
one when total contributions equals zero and zero when contributions is positive. The log of contributions equals the log of contributions when contributions is positive and zero when contributions equals zero. Their procedure is followed here. Equation (1) is estimated over the six years in the period 1998-2003.

The error term in the estimated cost function captures both inefficiency and random error. When the six random error terms obtained for each organization are averaged, the random error components tend to offset each other so that the average, $\ln \mu_{i}$, yields an estimate of the efficiency factor. This technique assumes that an organization's degree of efficiency persists so it can be captured in the averaging. Of course, over a sufficiently long period, organizational governance and market discipline change and so does efficiency. DeYoung (1997) considers the number of years required to minimize the influence of random error in the averaging and recommends six.

The efficiency factor, $\ln \mu_{i}$, is a multiplicative cost index: the index exceeds one when, on average, the achieved cost is greater than predicted and less than one when smaller than predicted. The smallest value of the cost index, $\mu_{M I N}$, can be used to construct the efficiency ratio for the i-th organization, (2) $E_{i}=\frac{\mu_{M I N}}{\mu_{i}}$. When the i-th organization defines the minimum cost index, $\mu_{i}=\mu_{M I N}$, so that $E_{i}=1$, and for all other organizations whose cost index exceeds the minimum, $\mu_{j}>\mu_{M I N}, 0<E_{j}<1$, so their efficiency registers less than one. Thus, higher values of the efficiency ratio correspond to lower values of the multiplicative cost index and indicate that any given amount of program services and contributions raised are achieved at lower administrative cost. Following Berger and Hannan (1998), the efficiency factor $\ln \mu_{i}$ is winsorized at the 5 percent and 95 percent levels to reduce the influence of outliers.

Panel A of Table 2 gives the details of the estimation of the administrative cost function. The translog specification allows for nonlinear administrative cost effects in logs and for interaction between program services and contributions. The estimated effect on administrative cost of a proportional increase in program services is given by the cost elasticity of program services:

$$
\frac{\partial \ln C}{\partial \ln \text { program }}=0.72292+(2)(0.00799)(\ln \text { program })+(-0.00373)(\ln \text { contributions }) \text {, }
$$


and of a proportional increase in total contributions, by the cost elasticity,

$$
\frac{\partial \ln C}{\partial \ln \text { contributions }}=0.15703+(2)(-0.00308)(\ln \text { contributions })+(-0.00373)(\ln \text { program }) \text {. }
$$

The overall cost elasticity, the effect on administrative cost of a proportional increase in both program and contributions is given by the sum of the elasticities. Panel B of Table 2 reports that, evaluated at the median values of program services and contributions, the overall cost elasticity is 0.968 . The inverse of the cost elasticity gives the degree of scale economies:

$$
\text { degree of scale economies }=\frac{1}{\frac{\partial \ln C}{\partial \ln \text { program }}+\frac{\partial \ln C}{\partial \ln \text { contributions }}} \text {, }
$$

which, evaluated at the median values of program and contributions, is 1.030 and significantly different from one. It ranges from a minimum of 0.886 to a maximum of 1.179 . Values greater than one indicate scale economies. The value 1.030 implies that a 10 percent increase in program services and contributions entails a 9.86 percent increase in administrative cost.

Panel C reports the administrative cost efficiency estimates: mean efficiency, 30.41 percent, and median, 23.29 percent, in a range of 7.50 percent, to a maximum of 100 percent. The commonly used performance metric, the ratio of program services expenses to total expenses, exhibits a mean of 83.30 percent, a median of 85.82 percent, and a range from 0.83 percent to 100.00 percent. The correlation between the performance metrics of administrative cost efficiency and the program expense ratio is 0.574 .

As a first step in examining the credibility of the cost efficiency metric, the sample is divided at the median value of efficiency into the more and less efficient halves to compare means of key variables that should be related to efficiency. Table 3 reports these comparisons. The more efficient group contains larger hospitals on average. They devote a higher proportion of total expenses to program services, 89.94 percent versus 76.66 percent, and operate with lower ratios of management expenses, 9.75 versus 22.40 percent, and fund-raising expenses, 0.32 versus 0.94 percent.

While there is no statistically significant difference in contributions as a percentage of total revenue, the more efficient hospitals on average spend 22.60 cents to raise a dollar of contributions while the less efficient spend on average 62.57 cents. There is no significant difference in their holdings of liquid assets as a 
proportion of total expenses. Compensation, though, is significantly higher at the more efficient hospitals. Since some hospitals do not report compensation and others report zero values, the values reported in the tables are computed only for hospitals that report positive values for the respective components of compensation. CEO compensation averages $\$ 285,532$ at the more efficient hospitals and $\$ 244,636$ at the less efficient. In turn, officers and directors compensation averages $\$ 669,872$ at the more efficient and $\$ 576,122$ at the less while average non-officer salaries are respectively $\$ 40,214$ versus $\$ 36,436$. These differences between the more and less administratively cost efficient appear intuitive and suggest that the efficiency metric accounts for a variety of factors that explain differences in the performance of charities.

\section{Administrative Cost Efficiency, Excess Cash Holdings, and Organizational Size}

As an additional test of the plausibility of the cost efficiency metric, the investigation of Core, Guay, and Verdi (2006) into the relationship of the program expense ratio and excess cash holdings is recast to examine the relationship of administrative cost efficiency to excess cash holdings. A finding similar to Core et al. that, as higher levels of excess cash are associated with lower ratios of program services, higher levels of excess cash are associated with lower administrative cost efficiency would add to the credibility of the efficiency metric as a measure of not-for-profit organizational performance. In addition, it would shed light on a difference aspect of charities' performance, their administrative performance relative to best practice. The efficiency metric does not simply substitute an administrative cost ratio for the program expense ratio, it considers how close a charity's administrative cost is to best practice cost. The finding that higher levels of excess cash are associated with lower administrative cost efficiency describes how the distance of such charities from the best practice frontier depends on their excess cash.

In this section, the data on 1028 hospitals are used to estimate a benchmark cash-holding equation and to measure "excess cash" - either positive or negative - from the residual of the benchmark equation. In turn, the measure of liquid assets in excess of the benchmark is used to investigate how such large cash holdings are related to the provision of program services, the distance of administrative costs from their best practice, and the size of managerial compensation. The agreement of the findings for program services and managerial compensation with the findings for administrative cost efficiency, and the overall agreement with the evidence of Core et al. suggests the plausibility of the administrative cost efficiency metric. 
The benchmark endowment (holdings of liquid assets) follows from a model developed by Fisman and Hubbard (2005) which emphasizes a precautionary motive for holding an endowment to maintain program services against variations in revenue from year to year. Core et al. specify a benchmark regression to capture the precautionary motive:

(6) $\left(100 \cdot\right.$ Endowment $\left._{i t}\right) /$ Expenses $_{i t}=\alpha_{0}+\alpha_{1} \ln$ Total Revenue $_{i t}+\alpha_{2}$ Debt $_{i t}+\alpha_{3}$ Revenue Risk $_{i t}$

$$
+\alpha_{4}\left(\text { Debt }_{i t}\right)\left(\text { Revenue Risk }_{i t}\right)+\sum \alpha_{j} \text { State }_{j}+\varepsilon_{i t}
$$

where endowment is stated as a percentage of total expense. Endowment, following Core, Guay, and Verdi (2006), consists of liquid assets at year-end: cash — non-interest-bearing balances (line 45), savings and cash investments (line 46), and investment securities (line 54). The benchmark endowment is estimated by twostage least squares. The log of total revenue (line 12) is treated as endogenous and, in addition to the other independent variables, lagged values of the log of assets and log of liabilities are used as instruments. Revenue risk is the standard deviation of revenue divided by its mean over five years. Hence, revenue risk has values only for 2002 and 2003. Debt is a dummy variable that equals one when the value of bond liabilities (line 64a) or mortgages and other notes (line 64b) is positive. The revenue risk variables limit the sample to two years: 2002 and 2003. Several zero values of assets and liabilities further reduce the number of observations to 1912. State and year dummies are also included.

The estimation reported in Table 4 shows that higher revenue risk is associated with higher benchmark holdings of liquid assets. For 96 percent of the organizations, access to debt reduces the benchmark need to hold liquid assets through the negative coefficient on the interaction of access to debt and revenue risk. The fitted benchmark equation is used to predict the holdings of liquid assets for all 1028 hospitals in the years 2002 and 2003 and to obtain their residuals. The residual defines “excess” liquid holdings as a percentage of total expenses, which can be negative as well as positive.

Jensen (1986) hypothesizes that excess holdings of cash reduce performance pressure on managers. In the case of not-for-profits, Core et al. look for evidence that organizations with excess endowment use the extra funds for program growth and investment in plant and equipment. They find little evidence that growth opportunities explain the higher holdings of liquid assets. Instead, they find that the proportion of expenses allocated to program services is negatively related to excess endowment, which implies that excess cash is 
related to higher administrative expenses. Moreover, executive compensation is positively related to excess endowment. They conclude that these relationships provide evidence that excess liquid holdings are related to agency problems.

As part of the investigation of the relationship of administrative cost efficiency to excess liquid holdings, the findings of agency problems related to excess endowment by Core et al. are reproduced using these newer data. Table 5 reports these relationships and compares the evidence obtained from the two performance metrics.

Table 5 contains several panels of results each of which focuses on a different characterization of the residual from the benchmark endowment equation. Core et al. define the excess endowment ratio in several ways. First, they use the residual, a continuous variable without transformation, in a regression of the program expense ratio on its lagged value and on lagged control variables. Second, they allow the coefficient on the lagged excess endowment ratio to differ for positive values and for negative values by creating a variable, lagged positive excess endowment, which is the residual value of the excess endowment ratio for positive values and zero for negative residual values, and lagged negative excess endowment, which is the value of the residual when it is negative and zero when positive. Third, values of the residual endowment ratio in the largest quartile are indicated by the value one of a dummy variable, Q4 excess endowment. Fourth, when an organization’s excess endowment residual appears in the fourth quartile for several continuous years, in the case of the current data, the two years the variable can be estimated, 2002 and 2003, a dummy, persistent excess endowment, takes the value one. And, when the residual appears in the fourth quartile for one but not both years, a dummy, transitory excess endowment, takes the value one.

The regressions reported in Table 5 each employ 1028 observations in the last year of the panel, 2003. The shortened sample results from two factors: first, the five years of data required to define revenue risk in the benchmark endowment regression leaves revenue risk defined only for 2002 and 2003; and, second, the two years of data, 2002 and 2003, required to measure persistent and transitory excess endowment leave these two variables measured only for 2003. Thus, the performance regressions are cross-sections.

In Panel A of Table 5, the program expense ratio and administrative cost efficiency are regressed on the lagged continuous value of the excess endowment residual, the lagged natural log of total expenses, and the squared natural log of total expenses, two control variables for size. Two additional control variables Core et 
al. used to test for accounting strategies organizations might use which would bias the results, the lagged ratio of contributions to total revenue and the lagged ratio of liabilities to total assets, are not used in these regressions. Their omission does not appreciably affect the results. In the program expense ratio regression, the coefficient on the continuous excess endowment residual is negative and statistically significant at 12 percent but not at conventional levels. However, the corresponding coefficient in the administrative cost efficiency regression is negative and statistically significant at better than 1 percent. To evaluate its economic significance, consider an increase in the excess endowment ratio from its minimum to its maximum value: administrative cost efficiency decreases 52.3 percent.

In Panel B the coefficient on the excess endowment ratio is broken down into coefficients for positivevalued and negative-valued ratios. These two coefficients provide evidence that the program expense ratio is not significantly related to either formulation of the excess endowment ratio while administrative cost efficiency is significantly negatively related to lagged positive excess endowment and not significantly related to the lagged negative excess endowment. Thus, the negative relationship of cost efficiency and excess endowment reported in Panel A appears to be driven by organizations whose holdings of liquid assets exceed the benchmark - that is, those with positive (residuals) excess endowments - rather than those with deficit holdings. The administrative cost efficiency ratio decreases 43.68 percent as the lagged positive excess endowment ratio increases from its minimum positive value to its maximum value.

In Panel $C$ the coefficients on the dummy variable that indicates holdings of liquid assets in the largest quartile of organizations provide evidence that, on average, these organizations have a statistically significant 2.65 percent lower program expense ratio and a 7.35 percent lower administrative cost efficiency ratio. In Panel D, membership in the fourth quartile is broken down into those organizations that belong to the fourth quartile for both years 2002 and 2003 where excess endowment can be computed - indicated by a dummy variable, permanent excess endowment, equal to one - and those that belong to the fourth quartile in either 2002 or 2003 but not both - indicated by a dummy variable, transitory excess endowment - equal to one. Neither the program expense ratio nor administrative cost efficiency is significantly related to transitory excess endowment; however, both performance metrics are significantly negatively related to permanent excess endowment. Organizations with liquid asset holdings in the highest quartile in both 2002 and 2003 have, on average, a statistically significant 3.49 percent lower program expense ratio and a 7.43 percent lower 
administrative cost efficiency ratio. Thus, weaker performance is not related to relatively large, temporary holdings of liquid assets, which may reflect growth opportunities in program and physical assets. Instead, as Jensen (1986) hypothesized, relatively large holdings of liquid assets that persist over time reduce performance pressure on management and often lead to poorer organizational performance.

In each of the panels, the relationship of the program expense ratio to size is given by the coefficients on the lagged log and squared lagged log of total expenses. These coefficients are quantitatively similar in each panel so the size effect is examined on in the first panel. In Panel A, the derivative of the program expense ratio with respect to organizational size, measured by the lagged log of the total expenses, is negative for smaller values of total expenses and positive for larger values. The derivative,

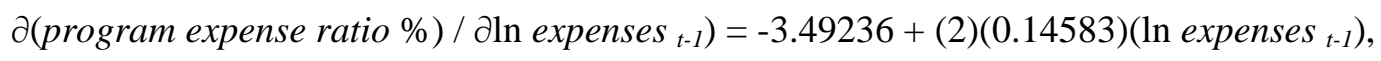

reverses sign at ln expenses $t_{t-1}=11.97$. Of the 1028 organizations in the regression in fiscal year 2003, 67 have total expenses under the value 11.97 while 961 exceed it. Thus, for larger hospitals, a total of 93.5 percent of the sample, the program expense ratio is positively related to size: larger expenses are associated with a higher program expense ratio and, hence, a lower administrative cost ratio.

A similar calculation in Panel A for administrative cost efficiency shows that the derivative,

$$
\partial(\text { administrative cost efficiency }) / \text { dln expenses }_{t-1}=-24.77615+(2)(0.73645)\left(\ln \text { expenses }_{t-1}\right) \text {, }
$$

reverses sign at ln expenses ${ }_{t-1}=16.82$. For 469 smaller hospitals, administrative cost efficiency is negatively related to size. However, as these hospitals’ size increases the negative correlation approaches zero. And, for the remaining 559 hospitals, 54.4 percent of the sample, cost efficiency increases with size.

The relationship of both performance metrics to organizational size, measured by total expenses is qualitatively similar. For most of the sample, the program expense as a percentage of total expenses increases with total expenses, which suggests that on average there are scale economies in administrative costs which permits the increase in program expense over administrative expense as institutions grow larger. And for slightly more than half the sample, the larger half, the administrative efficiency with which the hospitals produce program services increases with total expenses.

Table 6 divides the sample into quartiles by the amount of total expenses. Both the mean and median program expense ratio are highest in the largest quartile. The mean program expense ratio increases from the smallest to the largest quartile. Administrative cost efficiency is higher in the smallest and largest quartiles: 
apparently, mid-sized hospitals are at a disadvantage compared to small and large hospitals. This pattern is also found in commercial banking where small, community banks, which fill niche markets, and large money center banks are more efficient than mid-sized banks, which often become acquisition targets of large banks.

\section{Administrative Cost Efficiency and CEO Compensation}

Two distinctive characteristics of not-for-profit organizations, the absence of owners and the constraint preventing the distribution of profits and assets to employees, limit the ability of these organizations to tie pay to performance. ${ }^{2}$ OLS regressions reported in Table 7 investigate the relationship of CEO compensation to the two performance measures. CEO compensation sums salary, benefits, and expense allowance (Part V, amounts in columns $\mathrm{c}+\mathrm{d}+\mathrm{e}$ ). Many firms in the IRS data do not report compensation and some report zero values.

The sample used in the compensation regressions are restricted to firms that report positive CEO compensation. Robust standard errors are clustered at the firm level.

In Panel A, the coefficient on administrative cost efficiency, 7191.1, indicates that CEO compensation is positively related to administrative cost efficiency. However, the coefficient on the interaction of efficiency and size, 390.6, shows that the magnitude of the positive relationship is reduced as the organization's size increases. The estimated derivative of CEO compensation with respect to administrative cost efficiency is given by

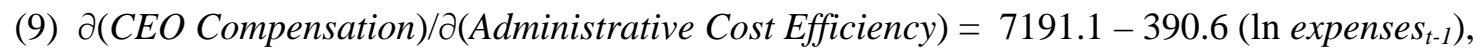

which is positive for values ln expenses $_{t-1}<18.41$. Thus, for the smaller 68 percent of the sample CEO compensation is positively related to administrative cost efficiency, and the derivative is statistically significant at better than 1 percent. On the other hand, the derivative is negative for the larger 32 percent of the sample, but the derivative is not significant different from zero over this range.

In Panel B, the coefficient on the program expense ratio, -9844.44, indicates that CEO compensation is negatively related to this measure of performance. However, the coefficient on the interaction of the program

\footnotetext{
${ }^{2}$ Hartzell, Parsons, and Yermack (forthcoming) find evidence that the Methodist Church appears to tie ministers' pay to performance.
} 
expense ratio and size, 581.66, complicates this relationship. The derivative of CEO compensation with respect to the program expense ratio is given by

(9) $\partial($ CEO Compensation $) / \partial\left(\right.$ Program Expense Ratio $\left._{t-1}\right)=-9844.44+581.66\left(\right.$ (n expenses $\left._{t-1}\right)$,

which is positive for values $\ln$ expenses $_{t-1}>16.92$. Thus, for the larger 70 percent of the sample, CEO compensation is positively related to the program expense ratio.

In both regressions, CEO compensation and organizational size are positively related. While the interaction term between size and cost efficiency is negative in the first regression, its magnitude is too small to switch the sign of the compensation-size correlation - that is, the value of cost efficiency at which the sign changes is outside the bound of the definition of cost efficiency.

\section{Conclusions}

The IRS Form 990 offers much useful information about not-for-profit organizations in the U. S. In particular, its functional breakdown of expenses into program, management, and fund raising permits a simple calculation of organizational performance in terms of the proportion of its expenses accounted for by program services. The program expense ratio points to the remaining proportion of expenses - administration - the sum of management and fund-raising expenses. A larger program expense ratio implies that the organization operates more efficiently. For a given amount of total expenses, a larger program expense ratio implies that less is spent on administration. And for a given amount of expenditure on program services, a larger program expense ratio entails smaller spending on administration.

While a larger program expense ratio captures better administrative cost efficiency, it does not gauge best-practice cost and the extent to which an organization's administrative costs exceed best practice. Based on the estimation of administrative cost as a function of program service expenditure and total contributions raised, this study uses the distribution free technique to identify organizations that produce program services at lowest administrative cost - at best practice - and to gauge other organizations' administrative cost in terms of this best-practice cost - their administrative cost efficiency. Thus, administrative cost efficiency supplements the program expense ratio as a performance metric by providing additional insight into organizational performance on the cost side. 
The empirical evidence on performance obtained from the administrative cost efficiency metric complements that of the program expense ratio and reinforces its credibility. The division of the sample into the more and less efficient organizations shows that the more efficient are larger, devote a higher proportion of total expenses to program services, operate with lower ratios of management expenses and fund-raising expenses, spend less to raise a dollar of contributions, and pay higher salaries.

The regressions of the program expense ratio and administrative cost efficiency on various characterizations of excess holdings of liquid assets agree: holdings of liquid assets in excess of the benchmark are associated with a lower program expense ratio and lower administrative cost efficiency. Administrative cost efficiency decreases 52 percent as the excess endowment ratio increases from its minimum to its maximum value. This relationship is driven by organizations whose holdings exceed the benchmark - those with positive residual endowment rather than deficit holdings. Organizations holding excess liquid assets in the largest quartile have a statistically significant 2.65 percent lower program expense ratio and a 7.35 percent lower administrative cost efficiency ratio. This result is driven by those organizations which persistently belong to the fourth quartile. Neither the program expense ratio nor administrative cost efficiency is significantly related to transitory excess endowment. Thus, weaker performance is not related to relatively large, temporary holdings of liquid assets, which may reflect growth opportunities in program and physical assets. Instead, as Jensen (1986) hypothesized, relatively large holdings of liquid assets that persist over time reduce performance pressure on management and often lead to poorer organizational performance. The agreement of the evidence on agency problems related to excess holdings of liquid assets from the program expense ratio and administrative cost efficiency reinforce the credibility of the latter as a measure of the performance of not-for-profit organizations. 


\section{Bibliography}

Altunbas, Yener, Lynne Evans, and Philip Molyneux, 2001, “Bank Ownership and Efficiency,” Journal of Money, Credit, and Banking 33, 926-954.

Berger, Allen N., 1993, “'Distribution-Free’ Estimates of Efficiency in the U.S. Banking System and Tests of the Standard Distributional Assumptions," Journal of Productivity Analysis 4, 261-292.

Berger, Allen N., and Timothy H. Hannan, 1998, "The Efficiency Cost of Market Power in the Banking Industry: A Test of the 'Quiet Life' and Related Hypotheses,” Review of Economics and Statistics 80, 454-465.

Berger, Allen N., and Loretta J. Mester, 1997, "Inside the Black Box: What Explains Differences in the Efficiencies of Financial Institutions,” Journal of Banking and Finance 21, 895-947.

Core, John E., Wayne R. Guay, and Rodrigo Verdi, 2006, “Agency Problems of Excess Endowment Holdings in Not-for-Profit Firms,” Journal of Accounting and Economics 41, 307-333.

Desai, Mihir, and Robert J. Yetman, 2006, “Constraining Managers without Owners: Governance of the Notfor-Profit Enterprise,” Working Paper, NBER

DeYoung, Robert, 1997, “A Diagnostic Test for the Distribution-Free Efficiency Estimator: An Example Using U. S. Commercial Bank Data,” European Journal of Operational Research 98, 243-249.

Fisman, R., and Hubbard, G., 2005, "Precautionary Savings and the Governance of Nonprofit Organizations," Journal of Public Economics 89, 2231-2243.

Hartzell, Jay C., Christopher A. Parsons, and David L. Yermack, 2010, "Is a Higher Calling Enough? Incentive Compensation in the Church,” forthcoming, Journal of Labor Economics,

Hughes, Joseph P., and Loretta J. Mester, 2009, “Efficiency in Banking: Theory, Practice, and Evidence,” Chapter 19, The Oxford Handbook of Banking, edited by Allen N. Berger, Philip Molyneux, and John Wilson, Oxford University Press.

Jensen, Michael C., 1986, “Agency Costs of Free Cash Flow, Corporate Finance, and Takeovers,”American Economic Review 76, 323-329.

Schmidt, Peter, and Sickles, Robin C., 1984, "Production frontiers and Panel Data," Journal of Business and Economic Statistics 2, 367-374.

Stiroh, Kevin J., 2000, “How Did Bank Holding Companies Prosper in the 1990s?” Journal of Banking and Finance 24, 1703-1745. 
Table 1

\section{Summary Statistics for the Full Sample}

The data consist of a balanced panel of 1028 not-for-profit hospitals over a six-year period 1998-2003. They were obtained from the IRS Form 990 filed annually by not-for-profit organizations and published by the National Center for Charitable Statistics. Total revenue is given on Form 990 at line 12; total expense at line 17, which sums program expense, line 13, management expense, line 14, and fund-raising expense, line 15. (Hospitals which report payments to affiliates, line 16, are dropped.) Administrative cost sums management and fund-raising expenses. Total contributions is given at line 1d. Endowment, following Core, Guay, and Verdi (2006), consists of liquid assets at year-end: cash-noninterest-bearing (line 45), savings and cash investments (line 46), and investment securities (line 54), which focuses on the potential of agency problems due to excess cash holdings.

\section{Panel A}

\begin{tabular}{lcrrr} 
Variable & N & Mean & Median & Std Dev \\
\hline Total Revenue & 6168 & $77,332,098$ & $23,149,532$ & $149,135,726$ \\
Total Expense & 6168 & $74,724,507$ & $22,494,743$ & $144,425,725$ \\
Program Expense & 6168 & $64,586,493$ & $18,310,289$ & $128,634,214$ \\
Administrative Cost & 6168 & $10,138,015$ & $3,130,709$ & $18,883,783$ \\
Management Expense & 6168 & $10,076,798$ & $3,109,150$ & $18,818,765$ \\
Fund-raising Expense & 6168 & 61,217 & 0 & 557,303 \\
Total Contributions & 6168 & $1,870,932$ & 123,952 & $13,398,351$ \\
Endowment (Liquid Holdings) & 6168 & $31,180,048$ & $2,576,138$ & $615,335,474$
\end{tabular}

\section{Panel B}

\begin{tabular}{|c|c|c|c|c|}
\hline Variable & $\mathrm{N}$ & Mean & Median & Std Dev \\
\hline Program Expense/Total Expenses & 6168 & 83.30 & 85.82 & 11.97 \\
\hline Administrative Cost/Total Expenses & 6168 & 16.70 & 14.18 & 11.97 \\
\hline Management Expense/Total Expenses & 6168 & 16.07 & 13.71 & 11.45 \\
\hline Fund-Raising Expense/Total Expenses & 6168 & 0.63 & 0.00 & 3.93 \\
\hline Total Contributions/Total Revenue & 6168 & 8.95 & 0.55 & 97.47 \\
\hline Endowment/Total Expenses & 6168 & 123.59 & 20.07 & 811.17 \\
\hline
\end{tabular}


Table 2

\section{Panel A: Estimation of the Administrative Cost Function}

To estimate the cost function, ordinary least squares with robust standard errors is applied to the data, which consist of a balanced panel of 1028 not-for-profit hospitals over a six-year period 1998-2003. The data were obtained from the IRS Form 990 filed annually by not-for-profit organizations and published by the National Center for Charitable Statistics. The dependent variable is administrative cost, which sums management (line 14) and fund-raising expenses (line 15). The two outputs are program expenses (line 13) and total contributions (line 1d). In order not to eliminate observations where total contributions equal zero, the log of total contributions is set equal to zero and an indicator variable for zero contributions is set equal to one. To account for differences across states in the cost of inputs and in the regulatory environment, state indicator variables are included as well as time indicator variables. They are not reported in the table.

\begin{tabular}{|c|c|c|c|c|}
\hline Variable & $\begin{array}{l}\text { Parameter } \\
\text { Estimate }\end{array}$ & $\begin{array}{l}\text { Robust } \\
\text { Standard } \\
\text { Error }\end{array}$ & t Value & $\operatorname{Pr}>\mid \mathrm{t}$ \\
\hline Intercept & -0.12187 & 0.80282 & -0.15 & 0.8793 \\
\hline Log Program Expenses & 0.72292 & 0.12028 & 6.01 & $<.0001$ \\
\hline Squared Log Program Expenses & 0.00799 & 0.00407 & 1.96 & 0.0495 \\
\hline Log Total Contribution & 0.15703 & 0.05091 & 3.08 & 0.0020 \\
\hline Squared Log Total Contributions & -0.00308 & 0.00198 & -1.55 & 0.1211 \\
\hline Zero Contributions Indicator & 0.59470 & 0.25739 & 2.31 & 0.0209 \\
\hline $\begin{array}{l}\text { Log Program Expenses } x \\
\text { Log Total Contributions }\end{array}$ & -0.00373 & 0.00186 & -2.01 & 0.0448 \\
\hline
\end{tabular}

State and Time Dummies - Yes

Number of Observations $=6168$

Adjusted R-square $=0.853$

\section{Panel B: Efficiency and Scale Economies Estimates}

The administrative cost elasticity of program services is $\partial \ln C_{t} / \partial \ln$ (program expenses) and the administrative cost elasticity of contributions is $\partial \ln C_{t} / \partial \ln$ (contributions). The estimate of scale economies is the inverse of the sum of output cost elasticities:

scale economies $=1 /\left[\partial \ln C_{t} / \partial \ln\right.$ (program expenses) $+\partial \ln C_{t} / \partial \ln ($ contributions $\left.)\right]$.

Elasticities Evaluated at Median Values of Program Services and Total Contributions

\begin{tabular}{ll}
\hline Adminstrative Cost Elasticity of Program Services & $0.946^{* * *}$ \\
Adminstrative Cost Elasticity of Contributions & $0.022^{\cdots}$ \\
Adminstrative Cost Elasticity of Program Services and Contributions & $0.968^{* *}$ \\
Degree of Scale Economies & $1.032^{* * *}$ \\
\hline
\end{tabular}

$* * *$ Significantly different from one at better than $p=.01$

' Significantly different from zero at better than $p=.01$

\section{Panel C: Efficiency Estimates}

Using the Distribution Free technique of estimating efficiency, the six random error terms obtained for each organization are averaged: since the random error components tend to offset each other, the average yields an estimate of the multiplicative efficiency factor, $\ln \mu_{i}$, which is a cost index. The smallest value of the cost index, $\mu_{\text {MIN }}$, is used to construct the efficiency ratio for the i-th organization, $E_{i}=\mu_{\text {MIN }} / \mu_{i}$.

\begin{tabular}{|c|c|c|c|c|c|c|}
\hline Variable & $\mathrm{N}$ & Mean & Median & Std Dev & Minimum & Maximum \\
\hline Total Revenue & 6168 & $77,332,098$ & $23,149,532$ & $149,135,726$ & 161 & $1,698,971,684$ \\
\hline Admin Cost Efficiency $\%$ & 6168 & 30.41 & 23.29 & 23.38 & 7.50 & 100.00 \\
\hline Program Expense Ratio \% & 6168 & 83.30 & 85.82 & 11.97 & 0.83 & 100.00 \\
\hline
\end{tabular}




\section{Panel D: Correlations}

The correlation of the two performance metrics, administrative cost efficiency and the program expense ratio, are examined in this table.

\begin{tabular}{|c|c|c|c|}
\hline & $\begin{array}{l}\text { Total } \\
\text { Revenue }\end{array}$ & $\begin{array}{l}\text { Administrative } \\
\text { Cost Efficiency }\end{array}$ & $\begin{array}{l}\text { Program Expense } \\
\text { Ratio }\end{array}$ \\
\hline Administrative & 0.0264 & 1.0000 & 0.5745 \\
\hline Cost Efficiency & 0.038 & & $<.0001$ \\
\hline Program Expense & 0.1353 & 0.5745 & 1.0000 \\
\hline Ratio & $<.0001$ & $<.0001$ & \\
\hline
\end{tabular}


Table 3

\section{Summary Statistics for Less and More Efficient Hospitals}

The data, which consist of a balanced panel of 1028 not-for-profit hospitals over a six-year period 1998-2003, were obtained from the IRS Form 990 filed annually by not-for-profit organizations and published by the National Center for Charitable Statistics. The charities are restricted to NTEEC category E22, hospitals.

The sample is divided at the median value of administrative cost efficiency. Administrative cost efficiency is estimated by the Distribution Free technique. Administrative cost is the sum of management (line 14) and fund-raising expenses (line 15).

Total expenses sums administrative cost and expenses due to the provision of program services (line 13). The ratio (stated as a percentage) of contributions to total revenue is given by the amounts on line $1 \mathrm{~d}$ and line 12 . Endowment, following Core, Guay, and Verdi (2006), consists of liquid assets at year-end: cash—non-interest-bearing (line 45), savings and cash investments (line 46), and investment securities (line 54). CEO total compensation sums salary, benefits, and expense allowance (Part V, amounts in columns c $+\mathrm{d}+\mathrm{e}$ ). Total compensation for officers and directors is given by line 25a. Average non-officer salary is the ratio of other salaries and wages (line 26a) divided by total full time equivalent employees (line 90b).

Between the more and less efficient samples, emboldened values of a variable indicate that they are significantly different from each other at the 1 percent level. ** indicates a significant difference at the 5 percent level while * indicates significance at the 10 percent level.

\section{Panel A: Less Cost Efficient Hospitals}

\begin{tabular}{|c|c|c|c|c|}
\hline Variable & $\mathrm{N}$ & Mean & Median & Std Dev \\
\hline Total Revenue & 3084 & $62,711,261$ & $24,772,562$ & $111,432,257$ \\
\hline Admin Cost Efficiency \% & 3084 & 14.61 & 14.59 & 4.75 \\
\hline Program Expenses/Expenses \% & 3084 & 76.66 & 79.46 & 12.19 \\
\hline Management Expenses/Expenses \% & 3084 & 22.40 & 20.05 & 11.70 \\
\hline Fund-Raising Expenses/Expenses $\%$ & 3084 & 0.94 & 0.00 & 4.94 \\
\hline Contributions/Revenue $\%$ & 3084 & 7.09 & 0.47 & 20.35 \\
\hline Fund-Raising Expenses/Contributions \% & 2596 & $62.57^{*}$ & 0.00 & 1192.68 \\
\hline Endowment/Expenses \% & 3084 & 119.15 & 19.72 & 420.45 \\
\hline CEO Total Compensation ${ }^{1}$ & 1148 & 244,636 & 195,850 & 189,064 \\
\hline Officers and Directors Compensation ${ }^{1}$ & 1957 & 576,122 & 323,274 & $1,132,372$ \\
\hline Average Non-Officer Salary ${ }^{1}$ & 2440 & 36,436 ** & 35,061 & 16,108 \\
\hline
\end{tabular}

${ }^{1}$ The summary statistics are computed only for observations that report positive compensation. Many observations failed to report compensation, and some reported values of zero

\section{Panel B: More Cost Efficient Hospitals}

\begin{tabular}{|c|c|c|c|c|}
\hline Variable & $\mathrm{N}$ & Mean & Median & Std Dev \\
\hline Total Revenue & 3084 & $91,952,935$ & $21,091,085$ & $177,891,313$ \\
\hline Admin Cost Efficiency $\%$ & 3084 & 46.21 & 36.39 & 23.91 \\
\hline Program Expenses/Expenses $\%$ & 3084 & 89.94 & 90.59 & 7.05 \\
\hline Management Expenses/Expenses $\%$ & 3084 & 9.75 & 9.22 & 6.72 \\
\hline Fund-Raising Expenses/Expenses $\%$ & 3084 & 0.32 & 0.00 & 2.52 \\
\hline Contributions/Revenue $\%$ & 3084 & 10.80 & 0.62 & 136.31 \\
\hline Fund-Raising Expenses/Contributions \% & 2659 & $22.50 *$ & 0.00 & 347.86 \\
\hline Endowment/Expenses \% & 3084 & 128.02 & 20.56 & 1067.43 \\
\hline CEO Total Compensation ${ }^{1}$ & 1008 & 285,532 & 220,754 & 264,214 \\
\hline Officers and Directors Compensation ${ }^{1}$ & 1697 & 669,872 & 341,452 & $1,149,180$ \\
\hline Average Non-Officer Salary ${ }^{1}$ & 2240 & 40,214 ** & 36,244 & 74,437 \\
\hline
\end{tabular}

${ }^{1}$ The summary statistics are computed only for observations that report positive compensation. Many observations failed to report compensation, and some reported values of zero. 


\section{Table 4}

\section{Panel A: Estimation of the Benchmark Endowment Equation}

The data, a balanced panel of 1028 not-for-profit hospitals (NTEEC category E22) over a six-year period 1998-2003, were obtained from the IRS Form 990 filed annually by not-for-profit organizations and published by the National Center for Charitable Statistics. The ratio (stated as a percentage) of endowment to total expenses (line 17) is the dependent variable. Endowment, following Core, Guay, and Verdi (2006), consists of liquid assets at year-end: cash—non-interest-bearing balances (line 45), savings and cash investments (line 46), and investment securities (line 54). The benchmark

endowment is estimated by two-stage least squares. The log of total revenue (line 12) is treated as endogenous and, in addition to the other independent variables, lagged values of the log of assets and log of liabilities are used as instruments. Revenue risk is the standard deviation of revenue divided by its mean over five years. Hence, revenue risk has values only for 2002 and 2003. Debt is a dummy variable that equals one when the value of bond liabilities (line 64a) or mortgages and other notes (line 64b) is positive. The revenue risk variables limit the sample to two years: 2002 and 2003. Several zero values of assets and liabilities further reduce the number of observations to 1912. State and year dummies are also included.

Dependent Variable: Endowment/Expenses x 100

\begin{tabular}{lrrrr}
\hline Variable & $\begin{array}{c}\text { Parameter } \\
\text { Estimate }\end{array}$ & $\begin{array}{r}\text { Standard } \\
\text { Error }\end{array}$ & $\mathrm{t}$ Value & $\mathrm{Pr}>|\mathrm{t}|$ \\
\hline Intercept & -30.8466 & 63.66390 & -0.48 & 0.6281 \\
Log Revenue & -0.35799 & 3.433147 & -0.10 & 0.9170 \\
Debt & 30.16410 & 21.17694 & 1.42 & 0.1545 \\
Revenue Risk & 1001.438 & 50.74173 & 19.74 & $<.0001$ \\
Debt x Revenue Risk & -828.453 & 76.15512 & -10.88 & $<.0001$ \\
\hline
\end{tabular}

State and Year Dummies - Yes

$\mathrm{R}^{2}=0.28720$

Number of observations $=1912$ 
Table 5

\section{Relationship of Performance to Various Measures of the Lagged Excess Endowment Residual}

The data, a balanced panel of 1028 not-for-profit hospitals (NTEEC category E22) over a six-year period 1998-2003, were obtained from the IRS Form 990 filed annually by not-for-profit organizations and published by the National Center for Charitable Statistics. These performance regressions use only the 1028 observations in 2003. The shortened sample results from two factors: first, the five years of data required to define revenue risk in the benchmark endowment regression leaves revenue risk defined only for 2002 and 2003; and, second, the two years of data, 2002 and 2003, required to measure persistent and transitory excess endowment leave these two variables measured only for 2003.

The percentage of total expenses accounted for by program expense consists of program expense (line 13) divided by total expense at line 17, multiplied by 100 . The administrative cost efficiency is based on the percentage of total expenses accounted for by administrative costs, the sum of management and fund-raising expenses -- lines 14 and 15 . It is estimated by the Distribution Free method.

Endowment, following Core, Guay, and Verdi (2006), consists of liquid assets at year-end: cash—non-interest-bearing (line 45), savings and cash investments (line 46), and investment securities (line 54), which focuses on the potential of agency problems due to excess cash holdings. Excess endowment (a ratio of endowment to total expenses) is the residual of the benchmark endowment regression. The residual is also defined by a variable, positive excess endowment, which equals the value of the residual when it is positive and zero when it is negative. Negative excess endowment equals the value of the residual when it is negative and zero when positive. Q4 excess endowment equals one when the organization's excess endowment is in the largest quartile of the data. Persistent excess endowment equals one when the organization's excess endowment places in the largest quartile in 2002 and 2003. Transitory excess endowment equals one when the organization's excess endowment places in the largest quartile in 2002 or 2003 but not both years.

White robust standard errors are reported in all panels.

\section{Panel A: Relationship of Performance to the Continuous Lagged Excess Endowment Residual}

Dependent Variable: Program Expense/Expense \%

\begin{tabular}{lrrrr}
\hline Variable & $\begin{array}{c}\text { Parameter } \\
\text { Estimate }\end{array}$ & $\begin{array}{r}\text { Standard } \\
\text { Error }\end{array}$ & $\mathrm{t}$ Value & $\mathrm{Pr}>|\mathrm{t}|$ \\
\hline Intercept & 94.11309 & 17.42688 & 5.40 & $<.0001$ \\
Log Expense $_{\mathrm{t}-1}$ & -3.49236 & 2.12293 & -1.65 & 0.1003 \\
Squared Log Expense $_{\mathrm{t}-1}$ & 0.14583 & 0.06418 & 2.27 & 0.0233 \\
Excess Endowment & -0.00232 & 0.00149 & -1.56 & 0.1203 \\
\hline
\end{tabular}

State Dummies - Yes

Number of Observations $=1028$

$\mathrm{R}$-Square $=0.1338$

Dependent Variable: Administrative Cost Efficiency $\%$

\begin{tabular}{lrrrr}
\hline Variable & $\begin{array}{r}\text { Parameter } \\
\text { Estimate }\end{array}$ & $\begin{array}{r}\text { Standard } \\
\text { Error }\end{array}$ & t Value & Pr $>|\mathrm{t}|$ \\
\hline Intercept & 234.31124 & 33.19272 & 7.06 & $<.0001$ \\
Log Expense $_{\mathrm{t}-1}$ & -24.77615 & 4.13331 & -5.99 & $<.0001$ \\
Squared Log Expense $_{\mathrm{t}-1}$ & 0.73645 & 0.12753 & 5.77 & $<.0001$ \\
Excess Endowment $_{\mathrm{t}-1}$ & -0.00871 & 0.00238 & -3.66 & 0.0003 \\
\hline
\end{tabular}

State Dummies - Yes

Number of Observations $=1028$

$R^{2}=0.0836$ 
Panel B: Relationship of Performance to Lagged Positive and Negative Excess Endowment Residual

Dependent Variable: Program Expense/Expense \%

\begin{tabular}{lrrrr}
\hline Variable & $\begin{array}{l}\text { Standard } \\
\text { Estimate }\end{array}$ & Error & $\mathrm{t}$ Value & $\mathrm{Pr}>|\mathrm{t}|$ \\
\hline Intercept & 94.47088 & 17.96911 & 5.26 & $<.0001$ \\
Log Expense $_{\mathrm{t}-1}$ & -3.52481 & 2.16586 & -1.63 & 0.1040 \\
Squared Log Expense $_{\mathrm{t}-1}$ & 0.14658 & 0.06512 & 2.25 & 0.0246 \\
Positive Excess Endow & -0.00245 & 0.00173 & -1.42 & 0.1573 \\
Negative Excess Endow & -0.00179 & 0.00373 & -0.48 & 0.6312 \\
\hline
\end{tabular}

State Dummies - Yes

Number of Observations $=1028$

$R^{2}=0.1338$

Dependent Variable: Administrative Cost Efficiency $\%$

\begin{tabular}{lrrrr}
\hline Variable & $\begin{array}{c}\text { Parameter } \\
\text { Estimate }\end{array}$ & $\begin{array}{c}\text { Standard } \\
\text { Error }\end{array}$ & t Value & $\mathrm{Pr}>|\mathrm{t}|$ \\
\hline Intercept & 239.81683 & 34.31092 & 6.99 & $<.0001$ \\
Log Expense $_{\mathrm{t}-1}$ & -25.27551 & 4.22934 & -5.98 & $<.0001$ \\
Squared Log Expense $_{\mathrm{t}-1}$ & 0.74799 & 0.12969 & 5.77 & $<.0001$ \\
Positive Excess Endow & -0.01057 & 0.00276 & -3.83 & 0.0001 \\
Negative Excess Endow & -0.00051 & 0.00626 & -0.08 & 0.9351 \\
\hline
\end{tabular}

State Dummies - Yes

Number of Observations $=1028$

$R^{2}=0.0853$

\section{Panel C: Relationship of Performance to Fourth Quartile Lagged Excess Endowment Residual}

Dependent Variable: Program Expense/Expense \%

\begin{tabular}{|c|c|c|c|c|}
\hline Variable & $\begin{array}{l}\text { Parameter } \\
\text { Estimate }\end{array}$ & $\begin{array}{r}\text { Standard } \\
\text { Error }\end{array}$ & t Value & $\operatorname{Pr}>|t|$ \\
\hline Intercept & 93.98147 & 16.75550 & 5.61 & $<.0001$ \\
\hline Log Expense $e_{t-1}$ & -3.42809 & 2.05268 & -1.67 & 0.0952 \\
\hline Squared Log Expense $e_{t-1}$ & 0.14368 & 0.06235 & 2.30 & 0.0214 \\
\hline Q4 Excess Endowment $t_{t-1}$ & -2.65038 & 1.06189 & -2.50 & 0.0127 \\
\hline
\end{tabular}

State Dummies - Yes

Number of Observations $=1028$

$\mathrm{R}^{2}=0.1375$

Dependent Variable: Administrative Cost Efficiency \%

\begin{tabular}{|c|c|c|c|c|}
\hline Variable & $\begin{array}{l}\text { Parameter } \\
\text { Estimate }\end{array}$ & $\begin{array}{r}\text { Standard } \\
\text { Error }\end{array}$ & t Value & $\operatorname{Pr}>|t|$ \\
\hline Intercept & 228.07709 & 32.40687 & 7.04 & $<.0001$ \\
\hline Log Expense $e_{t-1}$ & -23.90538 & 4.05334 & -5.90 & $<.0001$ \\
\hline Squared Log Expense $e_{t-1}$ & 0.71054 & 0.12555 & 5.66 & $<.0001$ \\
\hline Q4 Excess Endowment $t_{t-1}$ & -7.34831 & 1.91513 & -3.84 & 0.0001 \\
\hline
\end{tabular}

State Dummies - Yes

Number of Observations $=1028$

$\mathrm{R}^{2}=0.852$ 
Panel D: Relationship of Performance to Persistent and Transitory Lagged Excess Endowment

Dependent Variable: Program Expense/Expense \%

\begin{tabular}{|c|c|c|c|c|}
\hline Variable & $\begin{array}{l}\text { Parameter } \\
\text { Estimate }\end{array}$ & $\begin{array}{r}\text { Standard } \\
\text { Error }\end{array}$ & t Value & $\operatorname{Pr}>|t|$ \\
\hline Intercept & 94.16443 & 16.82080 & 5.60 & $<.0001$ \\
\hline Log Expense $e_{t-1}$ & -3.46586 & 2.06599 & -1.68 & 0.0938 \\
\hline Squared Log Expense $e_{t-1}$ & 0.14500 & 0.06271 & 2.31 & 0.0210 \\
\hline Persistent Excess Endow t $_{t-1}$ & $1-3.48774$ & 1.13153 & -3.08 & 0.0021 \\
\hline Transitory Excess Endow t $_{t-1}$ & $1-0.06238$ & 1.61806 & -0.04 & 0.9693 \\
\hline
\end{tabular}

State Dummies - Yes

Number of Observations $=1028$

$\mathrm{R}^{2}=0.1414$

Dependent Variable: Administrative Cost Efficiency $\%$

\begin{tabular}{lrrrr}
\hline & $\begin{array}{c}\text { Parameter } \\
\text { Estimate }\end{array}$ & $\begin{array}{r}\text { Standard } \\
\text { Error }\end{array}$ & t Value & $\mathrm{Pr}>|\mathrm{t}|$ \\
\hline Intercept & 227.22584 & 32.91539 & 6.90 & $<.0001$ \\
Log Expense & -23.82198 & 4.09671 & -5.81 & $<.0001$ \\
Squared Log Expense & 0.70839 & 0.12661 & 5.60 & $<.0001$ \\
Persistent Excess Endow & -7.74279 & 2.00877 & -3.85 & 0.0001 \\
Transitory Excess Endow & -1.77761 & 3.00752 & -0.59 & 0.5546 \\
\hline
\end{tabular}

State Dummies - Yes

Number of Observations $=1028$

$\mathrm{R}^{2}=0.0844$ 
Table 6

\section{Relationship of Performance to Size}

The data, a balanced panel of 1028 not-for-profit hospitals (NTEEC category E22) over a six-year period 1998-2003, were obtained from the IRS Form 990 filed annually by not-for-profit organizations and published by the National Center for Charitable Statistics. The percentage of total expenses accounted for by program expense consists of program expense (line 13) divided by total expense at line 17, multiplied by 100. The administrative cost efficiency is based on the percentage of total expenses accounted for by administrative costs, the sum of management and fund-raising expenses -lines 14 and 15. It is estimated by the Distribution Free method.

Largest Quartile Measured by Total Expenses

\begin{tabular}{lccrr}
\hline Variable & Mean & Median & Minimum & Maximum \\
\hline Log Expense t-1 $_{\text {Program Expense/Expense \% }}$ & 19.17 & 19.02 & 18.31 & 21.09 \\
Admin Cost Efficiency \% & 85.88 & 88.07 & 55.16 & 99.44 \\
\hline
\end{tabular}

Second Largest Quartile Measured by Total Expenses

\begin{tabular}{lccrr}
\hline Variable & Mean & Median & Minimum & Maximum \\
\hline Log Expense $_{\mathrm{t}-1}$ & 17.67 & 17.70 & 17.05 & 18.31 \\
Program Expense/Expense \% & 83.96 & 85.10 & 53.60 & 99.77 \\
Admin Cost Efficiency \% & 26.66 & 20.86 & 7.50 & 100.00 \\
\hline
\end{tabular}

Second Smallest Quartile Measured by Total Expenses

\begin{tabular}{|c|c|c|c|c|}
\hline Variable & Mean & Median & Minimum & Maximum \\
\hline Log Expense $e_{t-1}$ & 16.27 & 16.31 & 15.35 & 17.05 \\
\hline Program Expense/Expense \% & 82.43 & 84.63 & 48.03 & 99.60 \\
\hline Admin Cost Efficiency $\%$ & 25.41 & 21.13 & 7.50 & 100.00 \\
\hline
\end{tabular}

Smallest Quartile Measured by Total Expenses

\begin{tabular}{lccrr}
\hline Variable & Mean & Median & Minimum & Maximum \\
\hline Log Expense t-1 $_{\text {Program Expense/Expense } \%}$ & 13.04 & 13.17 & 9.09 & 15.33 \\
Admin Cost Efficiency \% & 79.98 & 84.97 & 1.39 & 99.97 \\
\hline
\end{tabular}


Table 7

\section{Relationship of CEO Compensation to Performance}

The data, a balanced panel of 1028 not-for-profit hospitals (NTEEC category E22) over a six-year period 1998-2003, were obtained from the IRS Form 990 filed annually by not-for-profit organizations and published by the National Center for Charitable Statistics. The sample of organizations used in these OLS regressions is restricted to those that report (positive) compensation for the CEO. Robust standard errors are clustered by firm. CEO compensation sums salary, benefits, and expense allowance (Part V, amounts in columns $\mathrm{c}+\mathrm{d}+\mathrm{e}$ ). The percentage of total expenses accounted for by program expense consists of program expense (line 13) divided by total expense at line 17, multiplied by 100 . The administrative cost efficiency is based on the percentage of total expenses accounted for by administrative costs, the sum of management and fund-raising expenses -- lines 14 and 15. It is estimated by the Distribution Free method.

Panel A: CEO Compensation and Administrative Cost Efficiency (\%)

Dependent Variable: CEO Compensation

\begin{tabular}{|c|c|c|c|c|}
\hline Parameter & Estimate & $\begin{array}{r}\text { Standard } \\
\text { Error }\end{array}$ & t Value & $\operatorname{Pr}>|t|$ \\
\hline Intercept & -1426058.9 & 109813.203 & -12.99 & $<.0001$ \\
\hline Log Expense $e_{t-1}$ & 95707.5 & 6294.837 & 15.20 & $<.0001$ \\
\hline Admin Cost Efficiency \% & 7191.1 & 1963.941 & 3.66 & 0.0003 \\
\hline Log Expense $_{t-1} \times$ Admin Cost Efficiency & -390.6 & 113.995 & -3.43 & 0.0006 \\
\hline
\end{tabular}

State Dummies - Yes

Number of Observations $=1814$

$R^{2}=0.3911$

Panel B: CEO Compensation and the Program Expense Ratio (\%)

Dependent Variable: CEO Compensation

\begin{tabular}{lrrrr}
\hline Parameter & Estimate & $\begin{array}{r}\text { Standard } \\
\text { Error }\end{array}$ & $\mathrm{t}$ Value & $\operatorname{Pr}>|\mathrm{t}|$ \\
\hline Intercept & -395358.79 & 243456.359 & -1.62 & 0.1046 \\
Log Expense ${ }_{\mathrm{t}-1}$ & 34931.23 & 15382.229 & 2.27 & 0.0233 \\
Program Expense/Expense \% & -9844.44 & 3219.208 & -3.06 & 0.0023 \\
Log Expense $_{\mathrm{t}-1}$ X Program Expense/Expense $\%$ & 581.66 & 197.691 & 2.94 & 0.0033 \\
\hline
\end{tabular}

State Dummies - Yes

Number of Observations $=1814$

$R^{2}=0.3893$ 